\title{
Results of the first air ion spectrometer calibration and intercomparison workshop
}

\author{
E. Asmi ${ }^{1,4}$, M. Sipilä ${ }^{1,}$, H. E. Manninen ${ }^{1}$, J. Vanhanen ${ }^{1,4}$, K. Lehtipalo ${ }^{1}$, S. Gagné ${ }^{1}$, K. Neitola ${ }^{1}$, A. Mirme ${ }^{2}$, \\ S. Mirme ${ }^{2}$, E. Tamm ${ }^{2}$, J. Uin ${ }^{2}$, K. Komsaare ${ }^{2}$, M. Attoui ${ }^{3}$, and M. Kulmala ${ }^{1}$ \\ ${ }^{1}$ Department of Physics, University of Helsinki, P.O. Box 64, 00014 Helsinki, Finland \\ ${ }^{2}$ Institute of Physics, Laboratory of Environmental Physics, University of Tartu, Ülikooli 18, 50090 Tartu, Estonia \\ ${ }^{3}$ Département de Physique Université Paris XII, Faculté des Sciences et Technologie, Paris, France \\ ${ }^{4}$ Finnish Meteorological Institute, P.O. Box 503, 00101 Helsinki, Finland \\ *also at: Helsinki Institute of Physics, University of Helsinki, P.O. Box 64, 00014 Helsinki, Finland
}

Received: 21 July 2008 - Published in Atmos. Chem. Phys. Discuss.: 11 September 2008

Revised: 9 December 2008 - Accepted: 9 December 2008 - Published: 9 January 2009

\begin{abstract}
The Air Ion Spectrometer (AIS) measures mobility and size distributions of atmospheric ions. The Neutral cluster and Air Ion Spectrometer (NAIS) can additionally measure neutral particles. The number of the (N)AIS instruments in the world is only 11 . Nevertheless, they are already widely used in atmospheric ion studies, particularly related to the initial steps of new particle formation. There is no standard method applicable for calibrating the ion spectrometers in the sub-3 $\mathrm{nm}$ ion range. However, recent development of high resolution DMAs has enabled the size separation of small ions with good mobility resolution. For the first time, the ion spectrometers were intercompared and calibrated in a workshop, held in January-February 2008 in Helsinki, Finland. The overall goal was to experimentally determine the (N)AIS transfer functions. Monomobile mobility standards, 241-Am charger ions and silver particles were generated and used as calibration aerosols. High resolution DMAs were used to size-separate the smaller $(1-10 \mathrm{~nm})$ ions, while at bigger diameters $(4-40 \mathrm{~nm})$ the size was selected with a HAUKE-type DMA. Negative ion mobilities were detected by (N)AISs with slightly better accuracy than positive, nonetheless, both were somewhat overestimated. A linear fit of slope of one to the whole dataset of mobilities suggested that $(\mathrm{N})$ AISs measured the negative mobilities $1.36 \pm 0.16$ times larger compared with the reference instruments. Similarly, positive mobilities were measured $1.39 \pm 0.15$ times larger compared with the reference instruments. The completely monomobile mobility standards were measured with
\end{abstract}

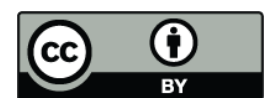

Correspondence to: E. Asmi (eija.asmi@helsinki.fi) the best accuracy. The (N)AIS concentrations were compared with an aerosol electrometer (AE) and a condensation particle counter (CPC). At sizes below $1.5 \mathrm{~nm}$ (positive) and $3 \mathrm{~nm}$ (negative) the ion spectrometers detected higher concentrations while at bigger sizes they showed similar concentrations as the reference instruments. The total particle concentrations measured by the NAISs were within $\pm 50 \%$ of the reference CPC concentration at $4-40 \mathrm{~nm}$ sizes. The lowest cut-off size of the NAIS in neutral particle measurements was determined to be between 1.5 and $3 \mathrm{~nm}$, depending on the measurement conditions and the polarity.

\section{Introduction}

Atmospheric ions are mainly studied due to their effects on aerosol particle processes. Ions affect the new particle formation (e.g. Kulmala et al., 2004a), particle growth (Laakso et al., 2003), and cloud processes and scavenging of particles (Andronache et al., 2006). Aerosol particles further affect the global climate, both with direct scattering effect, and indirect cloud effects, thus inducing a net negative radiative forcing. However, the low level of understanding the aerosol effects leads to large uncertanties in global climate model predictions (IPCC, 2007).

The first steps to understanding the role of ions and particles in global climate is to understand where, when and why particles are formed. Secondary small particle formation has been observed widely around the world (Kulmala et al., 2004b). The mechanisms behind it are, however, under discussion. The several suggested mechanisms include activation of stable neutral clusters (Kulmala et al., 2006;

Published by Copernicus Publications on behalf of the European Geosciences Union. 
Sihto et al., 2006), kinetic nucleation (Weber et al., 1996), ion induced (Laakso et al., 2002) and ion mediated nucleation (Yu and Turco, 2000), and binary and ternary homogeneous nucleation. The role of ions in particle formation is unquestioned, but the relative importance of ion-induced or ion-mediated particle formation is a question of debate. In addition, the recent laboratory experiments addressed that charged particles activate at lower supersaturation ratios than neutral (Winkler et al., 2008). Thus, ions more probably act as $\mathrm{CN}$ (condensation nuclei), and further more, as $\mathrm{CCN}$ (cloud condensation nuclei), having thus global effects. The (N)AIS has been proved particularly useful in experimental studies of the mechanisms of atmospheric particle formation (e.g. Kulmala et al., 2007a, 2005, 2004a).

The Air Ion Spectrometer (AIS) is designed to measure mobility distributions of small atmospheric ions and charged particles (mobility diameters $0.8-40 \mathrm{~nm}$ in NTP) (Mirme et al., 2007). The AIS is developed and manufactured by Airel ltd, a spin-off company of the University of Tartu. The AIS was first released in year 2003. Since then, instruments have experienced several improvements, the most important being the development of the Neutral cluster and Air Ion Spectrometer (NAIS). The NAIS is much similar to the AIS, but contains an improved inlet section which allows measurements of neutral particles as well. Currently, the number of AISs is six and NAISs five.

Allthough the (N)AIS is still a relatively new instrument, it has already been widely used. Measurements of atmospheric ions have been conducted at several sites in Europe, in boreal forest region (e.g. Kulmala et al., 2007a) and also in high altitudes (Venzac et al., 2007), in Australia (Suni et al., 2008) and South-Africa (Laakso et al., 2008), in marine environments (e.g. Vana et al., 2007), in a Moscow-Vladivostok train in Russia (Vartiainen et al., 2007), in Antarctica (Virkkula et al., 2007), and during hot-balloon flights scanning the vertical distribution of ions (Laakso et al., 2007). In addition, indoor ions have been studied (Hirsikko et al., 2007). The (N)AIS measurements have enhanced the knowledge of ion concentrations, sources, and prosesses, and their spatial and temporal variations.

As discussed above, there is a growing interest to study ions. The (N)AISs are used for ion studies as they are movable and relatively easy to use. Untill now, they have been calibrated separately after the manufacturing in the University of Tartu (Mirme et al., 2007). However, the calibrations are especially difficult at sizes of the smallest cluster ions of mobilities above $1 \mathrm{~cm}^{2} \mathrm{~V}^{-1} \mathrm{~s}^{-1}$ due to lack of reference instruments in this size range, and because size separation of such small particles is complicated. As the number of (N)AISs is growing, it would be of major importance to find congruent methods for verification and calibration of the instruments. In addition, in year 2008 all the (N)AISs are used simultaneously to gather information on ion concentrations in different parts of Europe. These measurements are a part of an integrated EU project, EUCAARI (Kulmala et al., 2007b). Therefore, it is also of importance for the project to characterise the operation of ion instruments.

During January-February 2008, the first (N)AIS calibration and intercomparison workshop was organised in Helsinki, Finland. In the workshop, 10 (N)AISs were compared and calibrated. Several methods were used to cover the whole size range of the instrument. The major improvements compared to the original calibrations were the possibility to use a high resolution DMA (Herrmann et al., 2000) and mobility standards (Ude and Fernández de la Mora, 2005) for calibrations of the (N)AISs in cluster and intermediate ion sizes. The purpose of this paper is to objectively present the results from these calibrations. The results can be later on utilised when the (N)AIS data from different sites, measured by separate instruments, are compared. The results will as well be of help in further development work of the (N)AISs and the data inversion.

\section{Ion spectrometers}

\subsection{Air Ion Spectrometer}

Air Ion Spectrometer (AIS) is developed for in-situ high time resolution measurements of ions and charged particles. The measured mobility range extends from 3.2 to $0.0013 \mathrm{~cm}^{2} \mathrm{~V}^{-1} \mathrm{~s}^{-1}$, corresponding mobility diameters $0.8-$ $40 \mathrm{~nm}$ in NTP-conditions. The AIS contains two identical analysers: one for measuring positive and one for measuring negative ions. Positive and negative ions are measured in parallel. The sample flow rate is $60 \mathrm{lpm}$ and it is divided between the two analysers. The sheath flow rate is $60 \mathrm{lpm}$ in both analysers, increasing the total one analyser flow rate to $90 \mathrm{lpm}$. The high flow rate is necessary to minimise the ion diffusion losses and for increasing the sensitivity to ion concentrations. The inner cylinder of the analyser is divided into 4 isolated sections and their voltages are kept unaltered during the whole measurement cycle. Measurable ions move towards the outer cylinder due to the radial electric field. The outer cylinder is divided into 21 isolated sections forming, together with their own electrometers, the 21 measuring channels of the analyser. The ions precipitate onto these sections according to their electrical mobilities, and the electrometers measure the currents induced by the ions. Before and after each ion measurement, an offset measurement is performed. An unipolar corona charger having a polarity opposite to that of the analyser, together with the sub-sequent electric filter, eliminates all charged particles from the input air. Thus the zero drift of the electrometers and the parasitic currents of the section isolators are measured. These parasitic currents are subtracted from the measured total currents and the corrected electrometer signals form the instrument record. Via the parasitic current dispersions the measurement random uncertainties are assessed. Using the mathematical model (instrument equation) of the (N)AIS and the 
transfer functions of the measurement channels, determined by the analyser geometry, flows, voltages, and ion losses, the instrument record is converted to mobility spectrum of the particles, which is a distribution density vector with 28 elements (Mirme et al., 2007). Time resolution is user defined, but the minimum for one ion spectrum is in the order of one minute, depending on the level of noise.

An improved version of the AIS is the Neutral cluster andAir Ion Spectrometer (NAIS). The NAIS has an additional charger-filter section in the inlet after the offset section providing a possibility to measure neutral particles as well. The first assumption is that the measurable particles are in charge equilibrium. They are further charged using an unipolar corona charger with ion currents of $-22 \mathrm{nA}$ (negative polarity) and $+25 \mathrm{nA}$ (positive polarity). The charging probability of particles then basically depends on the particle size, corona ion current and sample flow (exposure time). However, especially the smallest aerosol particles might not have reached the equilibrium state. The NAIS has thus an additional operation mode, where prior to charging, the measured particles are exposed to corona ions of opposite sign. The purpose is to bring the particles closer to the equilibrium charge distribution. The ion and offset modes are measured in the NAIS as in the AIS.

\subsection{Balanced scanning mobility analyser}

In addition to (N)AIS, the ion mobility distributions were measured with a Balanced Scanning Mobility Analyser (BSMA). The operation of the BSMA is more straightforward compared to the AIS. The BSMA has only one collecting electrode. This reduces the uncertanties caused by the possibly dissimilar electrometers. The voltage is scanned simultaneously in two similar analysers. A balancing bridge neutralises the current induced by the changing voltage. Thus, only the current induced by the ions is measured. The disadvantages of the BSMA compared to the AIS are the narrower measurement range $\left(0.03-3.2 \mathrm{~cm}^{2} \mathrm{~V}^{-1} \mathrm{~s}^{-1}\right)$, slightly decreased time resolution (minimum $10 \mathrm{~min}$ ), and sampling difficulties due to high inlet flow rate $(2400 \mathrm{lpm})$. However, the high flow rate minimizes the ion losses efficiently. Detailed discription of the BSMA is presented by (Tammet, 2006). Here, the BSMA served as a reference for the (N)AISs.

\section{Instruments for calibration of the ion spectrometers}

\subsection{High resolution DMAs}

High resolution differential mobility analysers (DMA) were used in mobility standard and transfer function calibrations. There were two DMAs available: high flow and high resolution Attoui DMA (ADMA) (Fernández de la Mora and Attoui, 2007), and very high resolution Herrmann DMA
(HDMA) (Herrmann et al., 2000). The ADMA has dimensions of the VIENNA-type DMA (Winklmayr et al., 1991; Reischl et al., 1997), but the inner electrode similar to the DMA used by Rosser and Fernández de la Mora (2005). The construction of the ADMA enables measurements up to larger sizes compared to the HDMA. The maximum aerosol flow in the ADMA is about $100 \mathrm{lpm}$ and the maximum sheath about $8000 \mathrm{lpm}$.

The HDMA was developed by Eichler and Fernández de la Mora (Eichler, 1997; de Juan and Fernández de la Mora, 1998; Fernández de la Mora et al., 1998). In the HDMA the maximum aerosol flow rate is about $15 \mathrm{lpm}$ and sheath about $2000 \mathrm{lpm}$. The HDMA has an improved mobility resolution compared to the ADMA, such that the transfer function is nearly monomobile (fullwidth at half maximum even $2 \%$ at $1.5 \mathrm{~nm}$ ). This makes it well suitable for calibration measurements. Both DMAs where used in calibrations and their results were compared.

\subsection{Mobility standards}

In cluster ion sizes the $(\mathrm{N}) \mathrm{AISs}$ were calibrated with the mobility standards. For positive clusters THAB (tetraheptyl ammonium bromide) monomers, dimers and trimers, TMAI (tetra-methyl ammonium iodide) monomers, and TDDAB (tetra-dodecyl ammonium bromide) monomers and dimers were chosen as calibration standards (Ude and Fernández de la Mora, 2005). These six monomobile singlycharged molecular clusters were chosen to comprehensively cover the whole cluster ion region measured by (N)AIS, and for the clarity of the peaks of their spectra. The molecules of THAB monomer, dimer, and trimer have mobilities $0.9709,0.6540$, and $0.5283 \mathrm{~cm}^{2} \mathrm{~V}^{-1} \mathrm{~s}^{-1}$, respectively, whereas TMAI monomer, and TDDAB monomer and dimer have mobilities $2.1786,0.7138$, and 0.4926 , respectively, at the room air temperature and pressure $\left(20^{\circ} \mathrm{C}, 1 \mathrm{~atm}\right)$. The positive mobility standard peaks are well characterised with a mass spectrometer and reported in the literature (Ude and Fernández de la Mora, 2005).

Negative mobilities of the THAB, TMAI and TDDAB are not as well established. By fixing the DMA voltage, clearly distinguishable peaks of their spectra were selected without the certainty of the peak composition. The mobility of the chosen peak was characterised based on the DMA calibration which relied on positive THAB spectra. Thus, in negative cluster calibrations, for example fragmenting might have resulted to incorrect results. Composition of the peaks should be later resolved with mass spectrometer. 


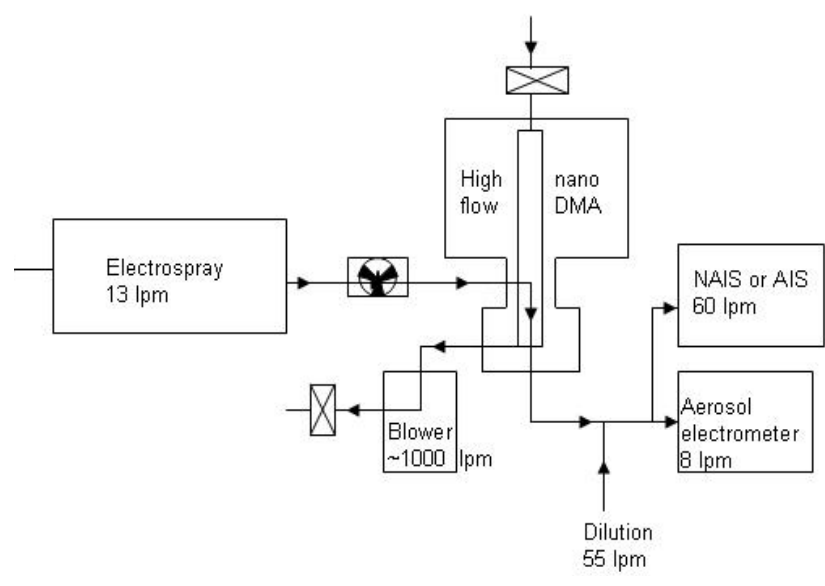

Fig. 1. (N)AIS mobility standard calibration set-up.

\section{Methods}

Several calibration methods were used. In the limited period of time, a part of the (N)AISs were calibrated more comprehensively than others. Table 1 summarises the calibrations performed for each individual (N)AIS.

\subsection{Determining the flows of the (N)AIS}

The sheath and the input flows of the (N)AIS are critical for the precise determination of the particle mobility and concentration. Thus, prior to calibrations, all (N)AISs were carefully cleaned and checked, and their flows were controlled.

The (N)AIS has a pump (blower) which runs all the flows. Five flow rates (sheath and output flows of both analysers and the total exhaust flow) are controlled with the venturi tubes. Each venturi tube has an individual calibration where the exact pressure drop, corresponding to the specified flow rate, is determined in NTP-conditions. In normal operation, only the exhaust flow rate is measured continuously, as it is the most sensitive to the changes of all flows. Based on these calibrations, the flows were adjusted in turns, keeping a constant overpressure $\left(80 \mathrm{~mm} \mathrm{H}_{2} \mathrm{O}\right)$ after the pump.

\subsection{Calibration of the (N)AISs with mobility standards}

Schematic figure of the calibration set-up is presented in Fig. 1. The THAB, TMAI, and TDDAB solutions were prepared with $99.9 \%$ pure methanol. The solutions were electrosprayed into clean pressurised air that was conducted to the Herrmann DMA. The inlet air flow rate was about $13 \mathrm{lpm}$. The voltage on the HDMA inner electrode was scanned and the sheath air flow rate controlled so that the mobility peaks were well distinguishable. The HDMA was operated in a closed loop and the sheath flow rate was in the order of $1000 \mathrm{lpm}$. The sheat flow rate was, however, not measured but the voltage scale was calibrated with the mobility stan- dards. The ion concentration in the sample air was measured with an aerosol electrometer (AE, TSI model $3068 \mathrm{~B}$ ). The HDMA voltage scale mobility correspondence was checked a minimum of two times per day using well defined and clearly distinguishable THAB spectra. This was especially important in measurements of negative standards where the peak mobilities are not established in the literature. The mobility scale remained usually constant troughout the day and the ion ratios (e.g. monomer/dimer) corresponded to those determined by (Ude and Fernández de la Mora, 2005).

The mobility was selected by setting the HDMA voltage. The HDMA selection was used to avoid having all the polymers in the same spectrum. The ion number concentrations were measured with the aerosol electrometer and with the (N)AISs. The sample flow was diluted with an additional clean pressurised air of about $55 \mathrm{lpm}$. The aerosol electrometer inlet flow rate was $8 \mathrm{lpm}$ and the (N)AIS inlet flow rate was $60 \mathrm{lpm}$. The measured ion concentrations were between 2000 and $30000 \mathrm{~cm}^{-3}$, depending on the solution. Measurements were performed with a moving setup. Several (N)AISs were set in a row and the measurement set-up was moved from one to another. By using such a method, the measurement conditions remained unchanged for all (N)AISs.

\subsection{High resolution DMA calibration}

The transfer function calibrations were done with a similar set-up than used in mobility standard calibrations (Fig. 1). Charged silver particles at sizes above $2 \mathrm{~nm}$ were produced with a tube furnace followed by a 241-Am bipolar charger. Below $2 \mathrm{~nm}$ in size, calibration ions were generated with a radioactive charger (241-Am). After separation with ADMA or HDMA the produced ions were used as a calibration aerosol. In most of the calibrations the size-separation was performed with the ADMA to reach smaller mobilities. Part of the calibrations were also performed with the HDMA, to test the effect of transfer function widening in the ADMA. The travelling time of the ions from the A/H DMA outlet to the (N)AIS inlet was approximatelly $1.5 \mathrm{~s}$. For each calibrated (N)AIS, approximately 100 mobilities in a logarithmically divided range from 0.015 to $3.2 \mathrm{~cm}^{2} \mathrm{~V}^{-1} \mathrm{~s}^{-1}$, were measured. The calibration ion concentration varied between 100 and $5000 \mathrm{~cm}^{3}$, being low at both ends and at around mobility $\left.1 \mathrm{~cm}^{2} \mathrm{~V}^{-1} \mathrm{~s}^{-1}\right)$. At this mobility, both the silver and charger ions were difficult to produce in high enough numbers with the provided methods.

\subsection{HAUKE DMA calibration with silver particles}

The set-up for measuring charged particles with a short HAUKE-type DMA is in most parts presented by Mirme et al. (2007). Distinct from the previous set-up, additional to aerosol electrometer, a TSI ultrafine condensation particle counter (CPC) model 3776 was used as a reference. The 
Table 1. Calibrations performed for different (N)AISs. In abbreviations “+” means positive ions, “-” negative ions, and "tf" trasfer function. In mobility standards, the number of standards used is marked for each (N)AIS. In other calibrations, "-" means "not done" and " $\times$ " means "done". In HAUKE DMA NAIS calibrations also particle mode was calibrated. AIS7 and NAIS5 were also tested for 10 and 20 nm ion (AIS) and particle (NAIS) concentration response using several concentrations.

\begin{tabular}{lcccccccccc}
\hline & AIS1 & AIS3 & AIS5 & AIS6 & AIS7 & NAIS1 & NAIS2 & NAIS3 & NAIS4 & NAIS5 \\
\hline + standards [number of stds'] & 3 & 3 & 5 & 7 & 4 & 4 & 5 & 4 & 5 & 5 \\
- standards [number of stds'] & - & 4 & 5 & 6 & 5 & 5 & 5 & 5 & 5 & 6 \\
+ HDMA tf (0.8-5 nm ions) & - & - & - & - & - & - & - & - & - & $\times$ \\
- HDMA tf (0.8-5 nm ions) & - & - & - & - & - & - & - & - & - & $\times$ \\
+ ADMA tf (0.8-10 nm ions) & - & - & $\times$ & - & - & - & - & $\times$ & $\times$ & $\times$ \\
- ADMA tf (0.8-10 nm ions) & - & - & $\times$ & - & - & $\times$ & - & $\times$ & $\times$ & $\times$ \\
+HAUKE DMA (4-40 nm) & $\times$ & $\times$ & $\times$ & - & $\times$ & $\times$ & $\times$ & $\times$ & $\times$ & $\times$ \\
- HAUKE DMA (4-40 nm) & - & $\times$ & $\times$ & - & $\times$ & $\times$ & $\times$ & $\times$ & $\times$ & $\times$ \\
HAUKE changing ion conc. & - & - & - & - & $\times$ & - & - & - & - & - \\
HAUKE changing part. conc. & - & - & - & - & - & - & - & - & - & $\times$ \\
\hline
\end{tabular}

3776 CPC had a lower cut-off size of $3 \mathrm{~nm}$. Aerosol electrometer flow rate was $3 \mathrm{lpm}$ and the CPC flow rate was $1.5 \mathrm{lpm}$. The electrometer and the CPC showed similar concentrations and thus, after a short time, only the CPC was used. Silver particles were generated with a tube furnace and charged with a bipolar 241-Am charger. The sample air flow rate in the DMA was $4 \mathrm{lpm}$ and the sheath air flow rate $20 \mathrm{lpm}$. The sample flow was diluted with an additional $63 \mathrm{lpm}$ clean pressurised air, leading to the total sample flow of $67 \mathrm{lpm}$. Of that flow, the (N)AIS used $60 \mathrm{lpm}$ and the reference instruments $4.5 \mathrm{lpm}$, such that there was an extra $2.5 \mathrm{lpm}$ to keep the system in small overpressure to prevent leakages. With this setup, the calibration aerosol concentrations reached from 2000 to about $10000 \mathrm{~cm}^{-3}$.

Additionally this setup was modified for neutral particle measurements by adding a neutraliser (14-C) after the DMA. Finally, the calibration aerosol concentration was changed by diluting the air coming from the tube furnace. Results were corrected with the CPC detection efficiency and the diffusion losses.

\subsection{Intercomparison}

Between the calibrations, the (N)AISs were measuring room air in the fifth floor garret (Physicum). Their computer clocks were checked regularily and inlets were placed close to each other. For comparison, the BSMA was also measuring in the same room. Even though the room was on the fifth floor, the cluster ion concentrations were exceptionally high. Occasionally, also particle formation events were recorded.

\section{Results}

\subsection{Response to standard ion peak mobilities}

The (N)AIS mobility responses to four most frequently measured positive and negative standards are plotted in Figs. 2 and 3. The (N)AIS positive ion peak mobility was in most cases within $\pm 10 \%$ of the standard mobility and deviations between instruments were small. The negative standard peaks (Fig. 3), and especially the THAB peak 3, were measured with lower accuracy. However, at least a part of the inaccuracy is thought to be due to the fragmentation of the selected molecules after extraction with the HDMA. The fragmentated, unknown clusters, can further enter the (N)AISs and affect the mobility of the measured spectra.

Even though the peak of the mobility corresponded well with the standards, the monomobile molecules extended to approximately 3 to 5 channels in the (N)AISs. This measurement precision was similar to both polarities. The shape of the measured ion distribution was close to lognormal. Thus, later on, the mobility measured with the (N)AIS will be described with the geometric mean mobility of the distribution. This decision was made, instead of selecting the peak value, to avoid the stepwise behaviour of the measured mobility.

\subsection{Detection of mobility and concentration of ions}

Verification of the (N)AIS mobility response to the above discussed mobility standards was straightforward, as the sample aerosol was purely monomobile. In contrast, using silver particles and charger ions in the calibrations leads to a nearly monodisperse sample aerosol. Then, the width of the distribution depends on the flows in the DMA. The charged silver particles and charger ions, which were mobility separated with the ADMA and HDMA, had a very narrow mobility distribution. Using the HAUKE-type DMA with 1/5 ratio between the aerosol and sheath flow rates for mobility separation led to broader mobility distribution. Despite the differences in the width of the original mobility distribution, only the peak mobility of generated ions was taken as a reference. The peak broadened in (N)AIS, as shown in Figs. 2 and 3 , and the geometric mean mobility was taken as a representative mobility for the measured mobility distribution. 

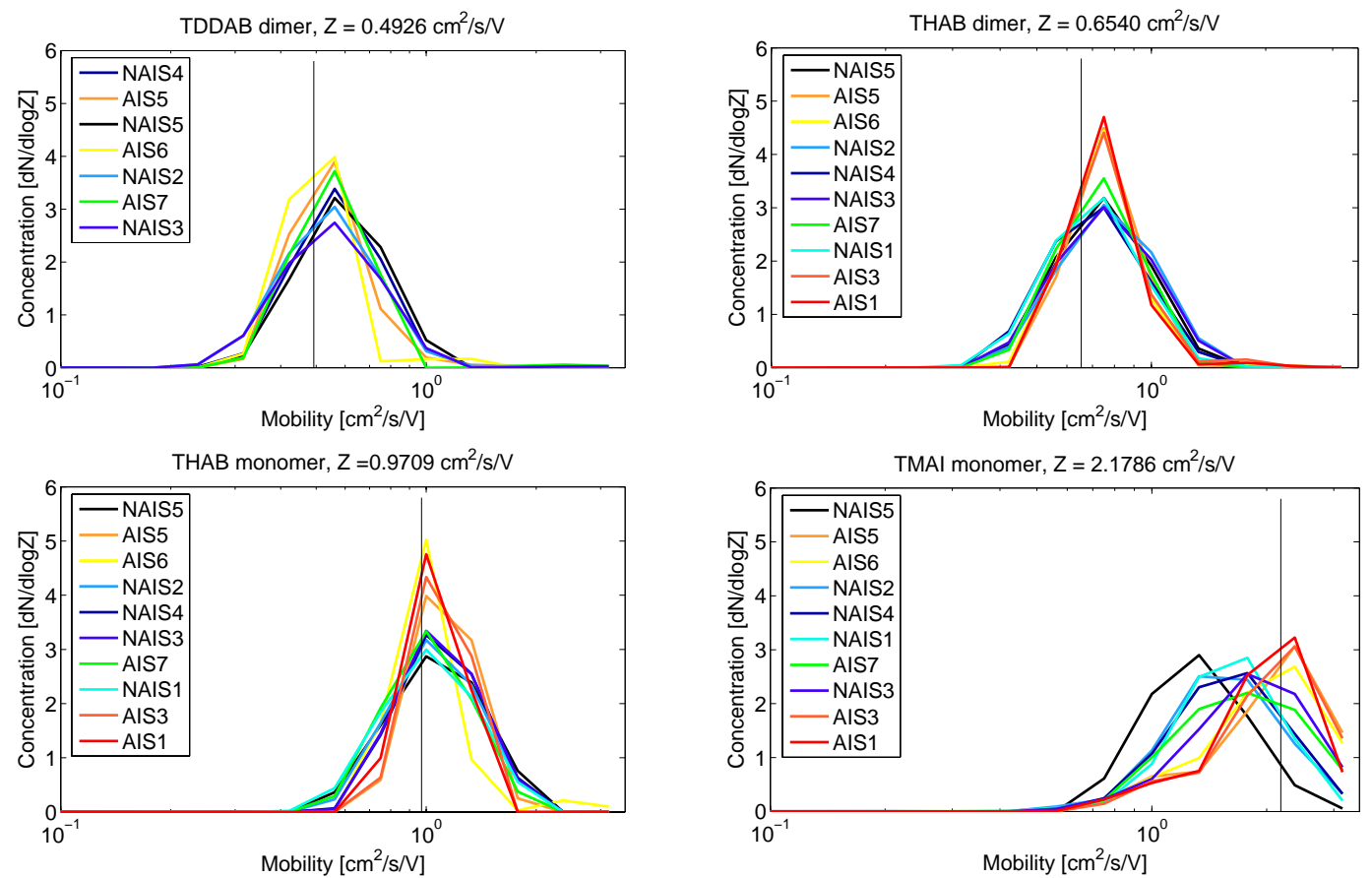

Fig. 2. Examples of four selected positive mobility standards measured with (N)AIS. The area of each measurement is normalised to unity and $\mathrm{y}$-axis shows the normalised concentration and $\mathrm{x}$-axis the mobility. The black vertical line shows the monomobile standard mobility.
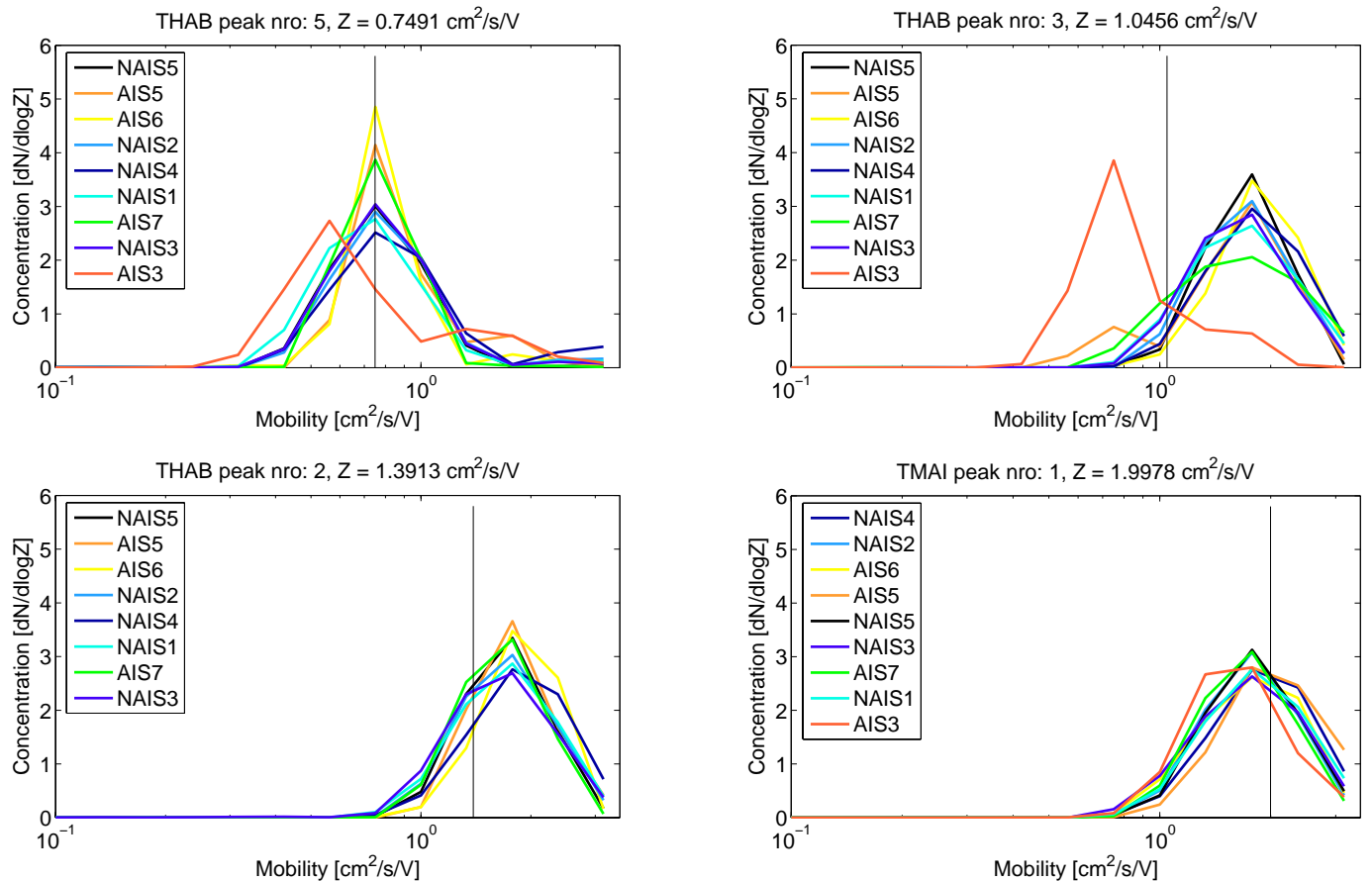

Fig. 3. Examples of four selected negative mobilities (unidentified standard peaks) measured with (N)AIS. The area of each measurement is normalised to unity and $\mathrm{y}$-axis shows the normalised concentration and $\mathrm{x}$-axis the mobility. The black vertical line shows the monomobile standard mobility. 


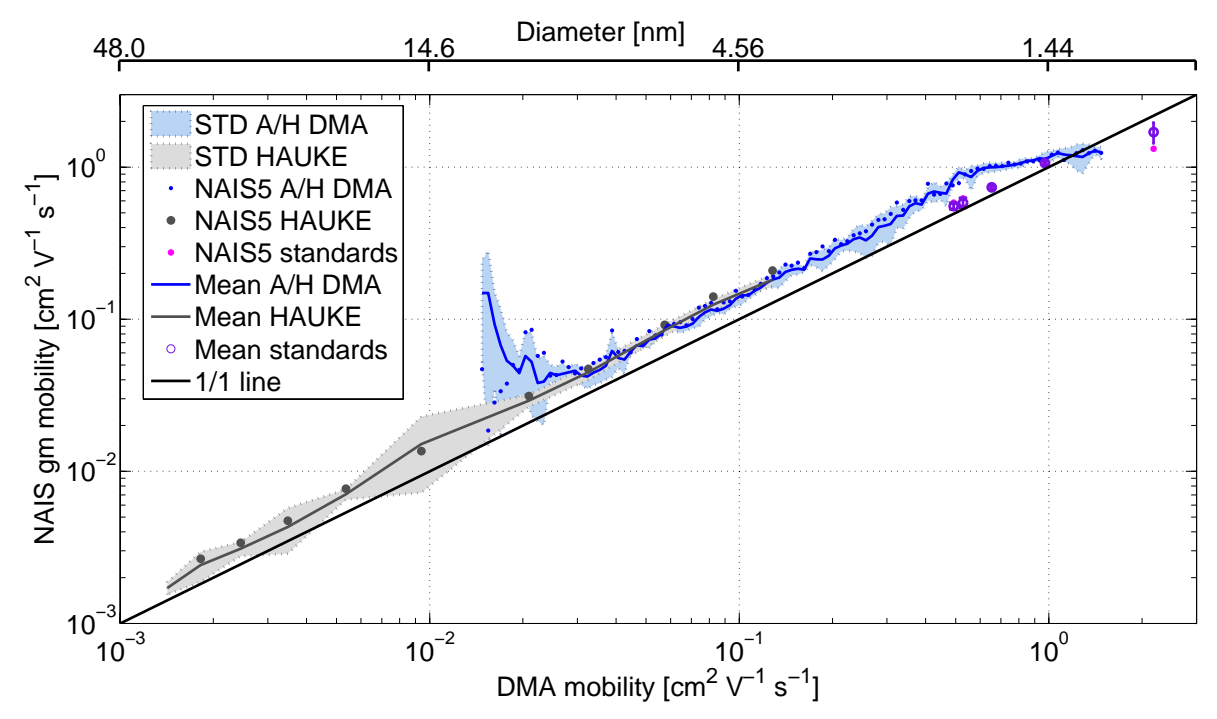

Fig. 4. Geometric mean mobility of positive ions (average and standard deviation between (N)AISs, and NAIS5 measurement as an example) measured with (N)AIS as a function of Attoui/Herrmann and HAUKE DMA selected mobility of silver particles and charger ions, and monomobile mobility standards.

This might have provided a small discrepancy between the HAUKE-type DMA and the (N)AIS mobility. Mobilities measured with the (N)AISs were plotted against the selected DMA peak mobilities or standard mobilities (Figs. 4 and 5).

Almost troughout the whole measured mobility range the (N)AISs detected the mobilities of positive charges larger compared to the DMA peak mobilities (Fig. 4). This behaviour was mainly constant with size - only in the largest mobilities the difference decreased. A linear fit of slope of one was fitted to all the data points in logarithmic scale in order to get an estimate for the mobility drift in the (N)AISs. This drift was $1.39 \pm 0.15$ times the mobility for positive polarity ions, where the error is estimated as a standard deviation of the residuals. The mobilities were measured more accurately in the smallest sizes and this decreased the drift value slightly. The HAUKE DMA and ADMA measurements overlapped well, confirming the reliability of the results. Due to the very low $\left(<50 \mathrm{~cm}^{-3}\right)$ calibration aerosol concentration below mobility $0.03 \mathrm{~cm}^{2} \mathrm{~V}^{-1} \mathrm{~s}^{-1}$ the ADMA calibration results were considered unrealiable. The shaded areas in Fig. 4 present the standard deviation between the (N)AISs. The median percentage of standard deviation versus mean positive ion mobility was $3.2,11.4$, and 9.3 in standard, high-resolution, and HAUKE DMA calibrations, respectively. The relatively small standard deviation gives evidence of the uniformity and reproducibility of the (N)AIS positive mobility measurement, especially when considering the short measurement time (about $1 \mathrm{~min}$ ) per spectrum. The mobility of the monomobile standards was detected with the best accuracy and precision. Thus it seems that the (N)AIS specrum moves towards smaller sizes only in case of non-monodisperse sample aerosol. The (N)AIS inversion is purely theoretical and seems to work best for the monomobile ions.

Theoretically, there is no difference in detection of negative and positive ions. However, the (N)AISs appeared to measure the mobilities of negative ions slightly more accurately (Fig. 5). The difference between the DMA selected and (N)AIS measured mobility was constant with size. The mobility drift obtained from the linear fitting was $1.36 \pm 0.16$ times the mobility for negative polarity ions. The finding is the same as in case of positive polarity that the (N)AIS measures non-monomobile molecules at too small sizes. However, the calibrations rely on the assumption that the ion mobility spectrum remains unaltered during the $1.5 \mathrm{~s}$ residence time between the outlet of the DMA and the inlet of the (N)AIS. It is difficult to characterise the stability of the ion distribution and thus in the cluster ion range the monomobile standards should be considered as the most reliable calibration method. The median percentage of standard deviation versus mean negative ion mobility was $6.4,9.5$, and 8.6 in standard, high-resolution, and HAUKE DMA calibrations, respectively, indicating similar variation between the (N)AIS measured mobilities as in case of positive ions. Again, most molecular clusters (standards) were measured correctly with the exception of two molecules. The two molecules were detected at similar mobilities as the corresponding charger ions. This might have been caused by molecule fragmenting and thus non-monomobile sample aerosol. A mass spectrometer spectra of the peaks could confirm this guess.

The (N)AIS concentration was integrated from the size distribution and compared with the CPC (in HAUKE DMA 


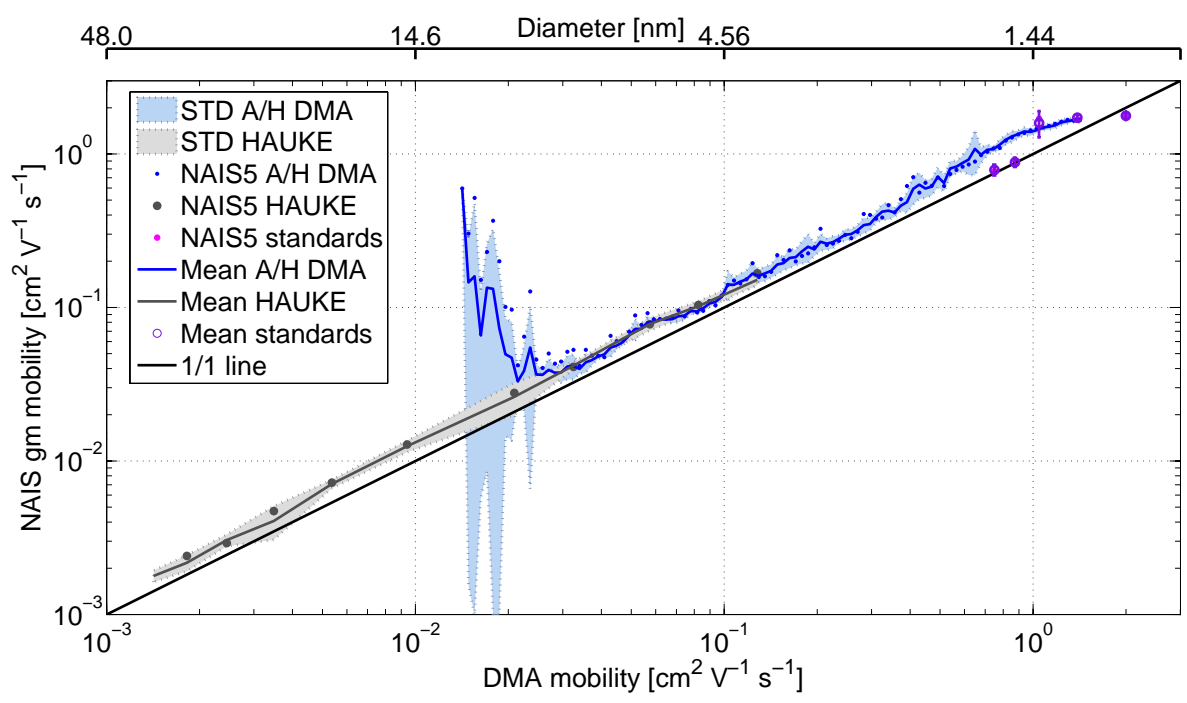

Fig. 5. Geometric mean mobility of negative ions (average and standard deviation between (N)AISs, and NAIS5 measurement as an example) measured with (N)AIS as a function of Attoui/Herrmann and HAUKE DMA selected mobility of silver particles, charger ions, and molecular clusters (standards).

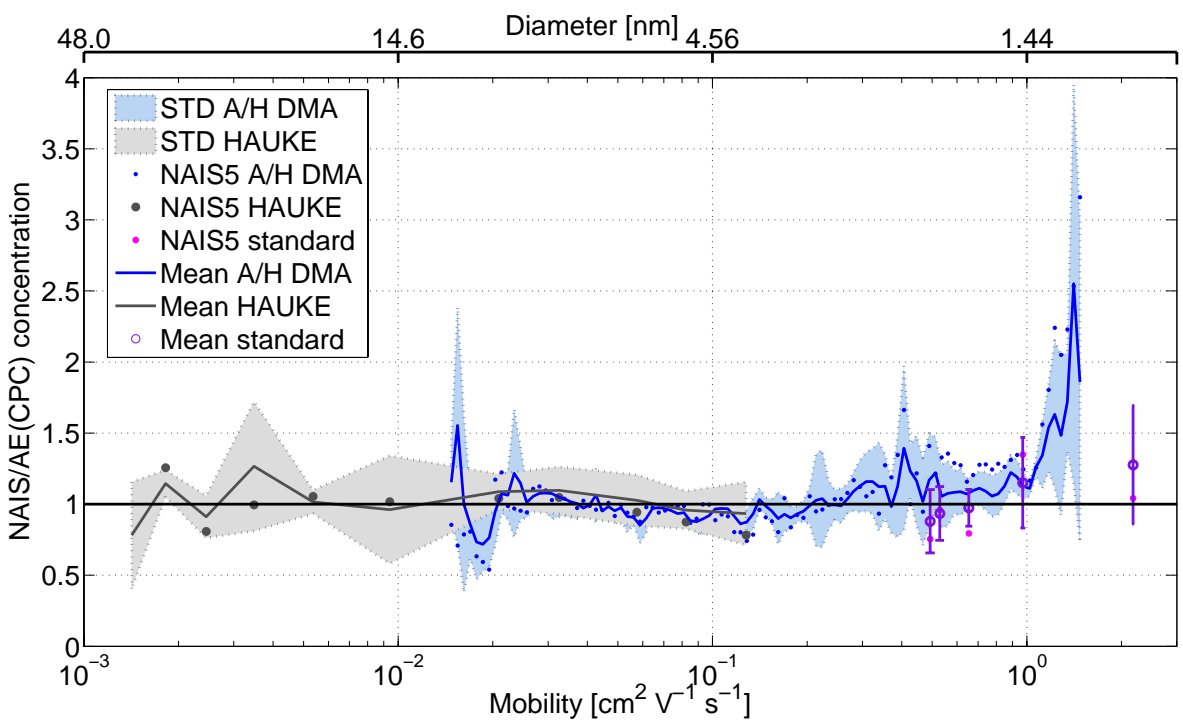

Fig. 6. Concentration of positive ions (average and standard deviation between (N)AISs, and NAIS5 measurement as an example) measured with (N)AIS as a function of Attoui/Herrmann and HAUKE DMA selected mobility of silver particles and charger ions, and monomobile mobility standards.

calibrations) and the aerosol electrometer (in A/H DMA and standard calibrations) measured concentrations (Figs. 6 and 7). For most mobilities this ratio was close to one. The median of the average negative ion concentration ratios obtained from different calibration set-ups were $1.5 \pm 0.2$, $1.1 \pm 0.1$, and $1.0 \pm 0.1$, for standards, high-resolution DMA, and HAUKE DMA, respectively. Same numbers for positive ion concentration ratios were $0.9 \pm 0.2,1.0 \pm 0.1$, and
$1.0 \pm 0.2$. Only at the largest mobilities (i.e. smallest sizes) the ratio increased. This increase began at smaller mobility $\left(0.4 \mathrm{~cm}^{2} \mathrm{~V}^{-1} \mathrm{~s}^{-1}\right)$ in negative ions than in positive ions (where the increase began at mobility $1 \mathrm{~cm}^{2} \mathrm{~V}^{-1} \mathrm{~s}^{-1}$ ). At the largest measured mobility the (N)AISs detected on average two times the concentration of the aerosol electrometer. The first suspected reason for this was the electrometer losses. However, in tests the electrometer signal became 


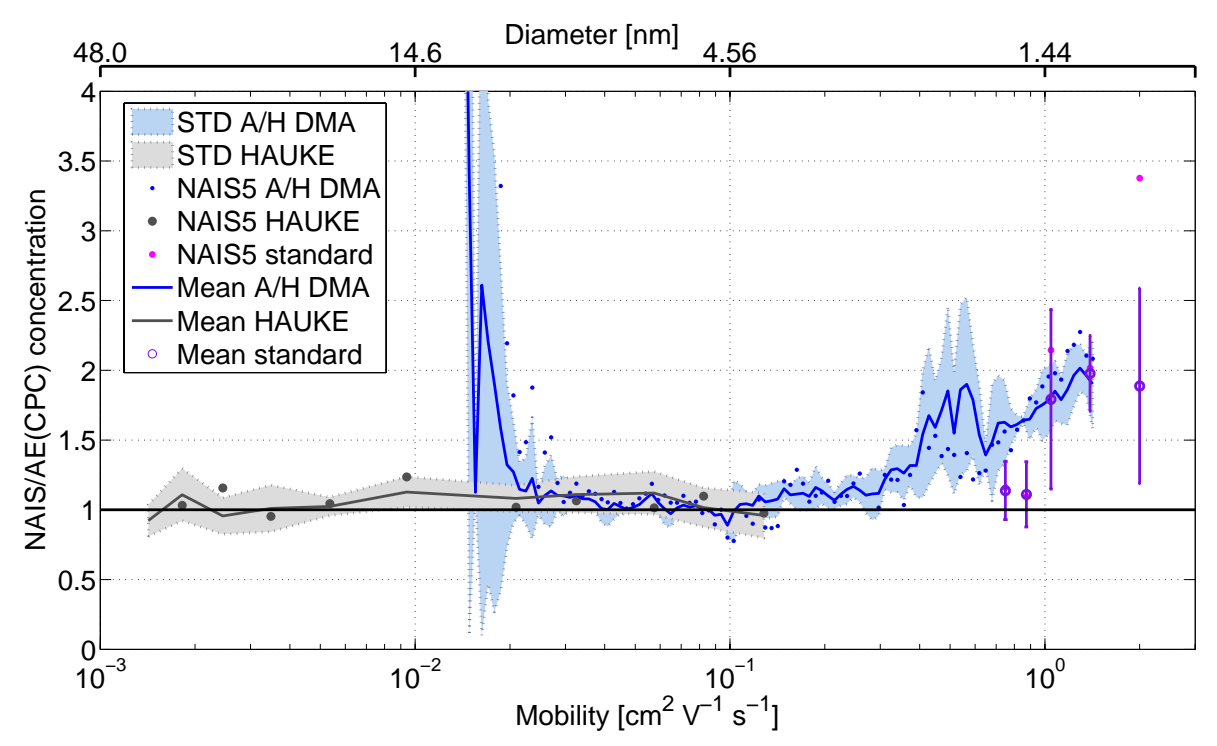

Fig. 7. Concentration of negative ions (average and standard deviation between (N)AISs, and NAIS5 measurement as an example) measured with (N)AIS as a function of Attoui/Herrmann and HAUKE DMA selected mobility using silver particles, charger ions, and molecular clusters (standards).

flow independent at lower flowrate than was used in here, making it an unlikely cause. In addition, the calibration ion concentrations were decreased to below $500 \mathrm{~cm}^{-3}$ at mobilities larger than $1 \mathrm{~cm}^{2} \mathrm{~V}^{-1} \mathrm{~s}^{-1}$. This had probably a small effect, as low concentration might have induced a relatively higher noise resulting in small background in the (N)AIS signal. This background was irrelevant at higher concentrations and was partly due to the unavoidable electrometer noise, partly the processing of negative values in the inversion. Lower concentration also led to larger standard deviation. Small increase in the ratio was, however, detected when using mobility standards as well. Thus the increase is mainly suspected to be caused by the (N)AIS inversion, not related to the noise. In contrast, the increase detected below mobility $0.03 \mathrm{~cm}^{2} \mathrm{~V}^{-1} \mathrm{~s}^{-1}$ was most probably due to low calibration aerosol ion concentrations. Otherwise, the HAUKE and A/H DMA results overlapped well.

It is interesting to look at the above results in the context of the commonly measured atmospheric cluster ion mobilities and numbers. As if it seems that the (N)AISs overestimate the ion mobility this would mean the atmospheric ions are actually bigger than previously thought based on (N)AIS measurements. Typically in the atmosphere the positive cluster are bigger than the negative clusters. The above result of the bigger drift of the mobility in positive polarity would suggest that the difference between polarities is even higher than previously measured. Additionally, especially the concentration of negative cluster ions might have been overestimated in the previous (N)AIS measurements. Interestingly, this would suggest a decreased fraction of the ion-induced nucleation mechanism pathway.

\subsection{Detection of total particle concentration}

The NAIS can also measure total particle number size distributions. The lowest detection limit is defined by the maximum size of the charger ions. In calibrations, the NAIS concentration response was tested for 11 DMA selected sizes, beginning at $4 \mathrm{~nm}$. After the DMA, particles were brought to charge equilibrium with a neutraliser. This is critical, as the number concentration in the NAIS is calculated based on the assumption that the particles are initialially in charge equilibrium. Even a slight overcharge in initial condition can affect the charging probability, and furthermore, the measured particle concentration. In case of initially overcharged aerosol the NAIS overestimates the particle concentration.

The concentration measured by the NAIS was calculated by integrating over all sizes above $3 \mathrm{~nm}$. The lower cut-off size of $3 \mathrm{~nm}$ was set to get rid of the ions produced in the NAIS corona charger, and in the bipolar charger prior to the NAIS. However, even lower (1.5-2 nm) cut-off size can be achieved if the particle concentration is high at the smallest sizes, as will be later presented. The average concentrations detected by the NAISs were within $\pm 50 \%$ of the reference CPC (Fig. 8). At sizes below $10 \mathrm{~nm}$ the NAISs showed smaller concentrations than the CPC. At small sizes the $3 \mathrm{~nm}$ cut-off size, and the transfer function broadening, probably caused a part of the particles to fall out from the integrated size range, resulting in underestimation of the particle number. At larger sizes the NAISs showed slightly higher concentrations than the CPC, typically some tens of percents. One explanation for the higher number concentration measured by the NAISs was the background in particle 


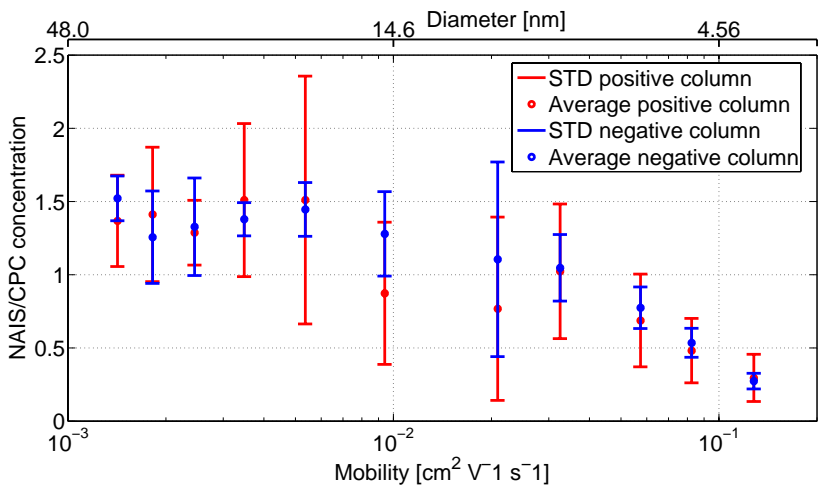

Fig. 8. Average concentration of all particles (charged=neutral) and standard deviation between the five NAISs as a function of HAUKE DMA selected mobility of silver particles. Particles measured in NAIS positive and negative column are presented separatelly.

measuring mode. When the NAISs were used to measure ion concentrations, a small background, caused by the noise of the electrometers, was always present. When ion concentrations were multiplied with charging probabilities, the background became more significant. This also leads in additional broadening of the measured particle number size spectra. In addition, occasionally the particles were not in equilibrium but a clear difference between negative and positive ion numbers was observed. As mentioned before, this might create overestimation of the number concentration. However, this effect should be most pronounced at the smallest sizes, oppositely as detected here.

\subsection{Transfer functions of the measurement channels}

A transfer function for each measurement channel of the selected (N)AISs was calculated based on the A/H DMA densely size separated silver and charger ion concentrations. Positive and negative ion transfer functions for the NAIS5 channels 5, 9, and 13 are presented in Fig. 9. In the theoretical transfer functions the ion losses in the inlet are taken into account while the measured transfer functions are based on raw current signal values in each electrometer, without separating the ion losses. This increases the area of the theoretical transfer functions compared to the measured functions particularly at the smallest sizes, but does not affect the shape. The theoretical transfer functions are logarithmically nearly symmetrical around the peak value whereas the measured transfer functions deviated, showing a tail towards the smaller mobilities. In addition, especially in the positive polarity, the peak of the distribution moved towards the tail. This resulted to the detection of the ions at slightly larger mobilities than their actual mobility, and especially in positive polarity. The shape of the transfer function and the observed tail, explain much of the mobility drift observed in Figs. 4 and 5. For instance, the electrometer of the channel num-

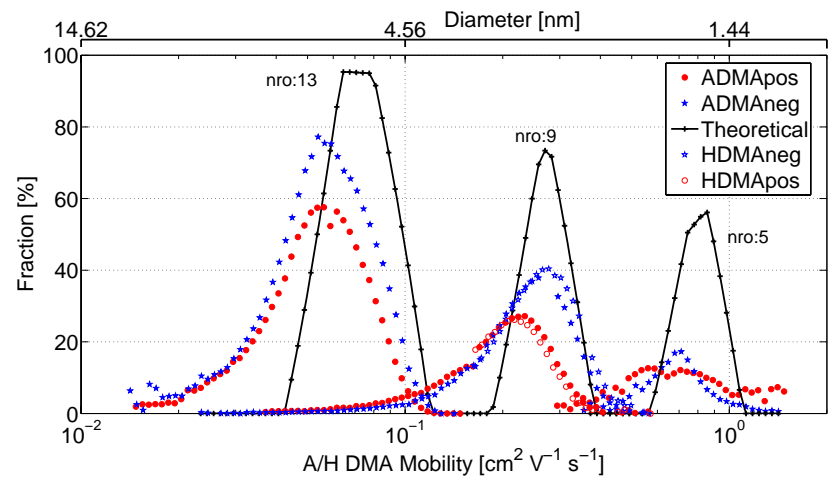

Fig. 9. Measured transfer functions for positive and negative ions and theoretical transfer functions for electrometers of the channels nro 5, 9, and 13. In theoretical transfer functions the ion losses in the inlet are additionally included, increasing the area compared to the measured transfer functions.

ber 9 would in theory only detect ions of mobilities between about 0.2 and $0.4 \mathrm{~cm}^{2} \mathrm{~V}^{-1} \mathrm{~s}^{-1}$ but in reality, also ions of mobilities below $0.1 \mathrm{~cm}^{2} \mathrm{~V}^{-1} \mathrm{~s}^{-1}$ were detected at this channel. One explanation for the deviation could be turbulence in the inlets of the (N)AIS analysers, which might push the ions towards the outer cylinder. This would demand more work to resolve in a way that all other extrinsic factors, possibly affecting the results, would be excluded, such as the ion stability issues.

As the resolution of the Attoui DMA was lower than the Herrmann DMA, the calibrations were done with both DMAs. Results were non-divergent between the DMAs, which indicates that the resolution of the Attoui DMA can be considered sufficient, i.e. the ADMA transfer function widening can be ignored. In Fig. 9 the transfer function determined with the Herrmann DMA is only presented for channel number 9 but the conclusion applies to other channels as well. Also, the transfer functions of all calibrated (N)AISs had a similar shape, as the results presented in earlier subsections, already suggested.

\subsection{Calibrations with reduced calibration aerosol concen-} tration

Most calibrations were performed with relatively high concentrations if compared with the atmospheric ion concentrations. This minimises the statistical errors but also arises a question if the (N)AISs respond consistently to reduced concentrations. To test this, the $10 \mathrm{~nm}$ charged and neutral silver particle concentration was decreased by diluting the sample air and further, size separated with the HAUKE-type DMA. A decrease in the negative ion concentration from 1000 to about $100 \mathrm{~cm}^{-3}$ resulted in congruent decrease of the AIS7 and the CPC concentration (Fig. 10). When the concentration decreased further to below $10 \mathrm{~cm}^{-3}$ the AIS7 was unable to 


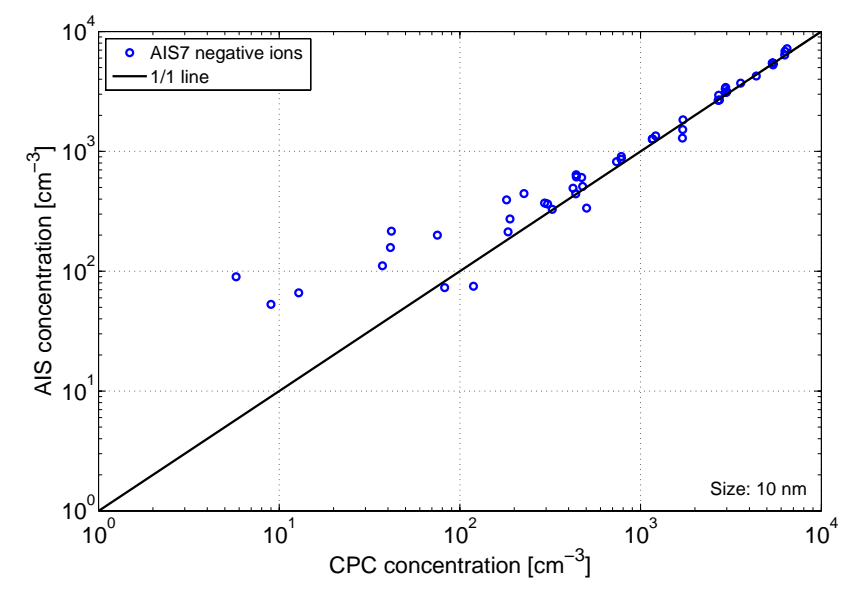

Fig. 10. Negatively charged $10 \mathrm{~nm}$ silver particle concentration measured with AIS7 as a function of CPC concentration.

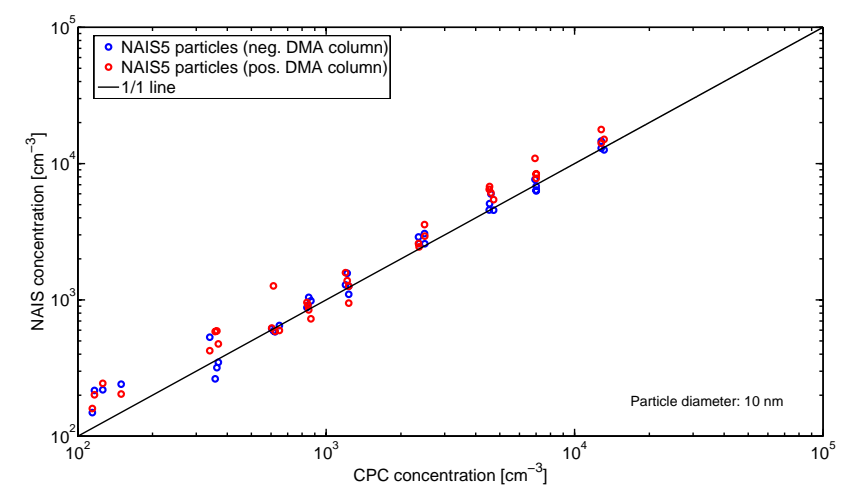

Fig. 11. Total (neutral+charged) $10 \mathrm{~nm}$ silver particle concentration measured with NAIS5 negative and positive column as a function of CPC concentration.

follow the CPC concentration and recorded higher numbers of ions. This same phenomenon was detected in case of the NAIS5 in particle measuring mode (Fig. 11). The concentration followed the CPC concentration down to $300 \mathrm{~cm}^{-3}$ but below the NAIS5 detected more particles. The background appears to be caused by the electrometer noise, which normally always exists. In case of neutral particle measurements the noise becomes even more significant due to the low charging probability of such small particles. The background complicates reliable measurement of very low concentrations with the (N)AISs. At low concentrations, the measurement time per spectrum should be increased and the measurement signal should conquer the noise signal. In these calibrations, only one minute measurement time per spectrum was used.

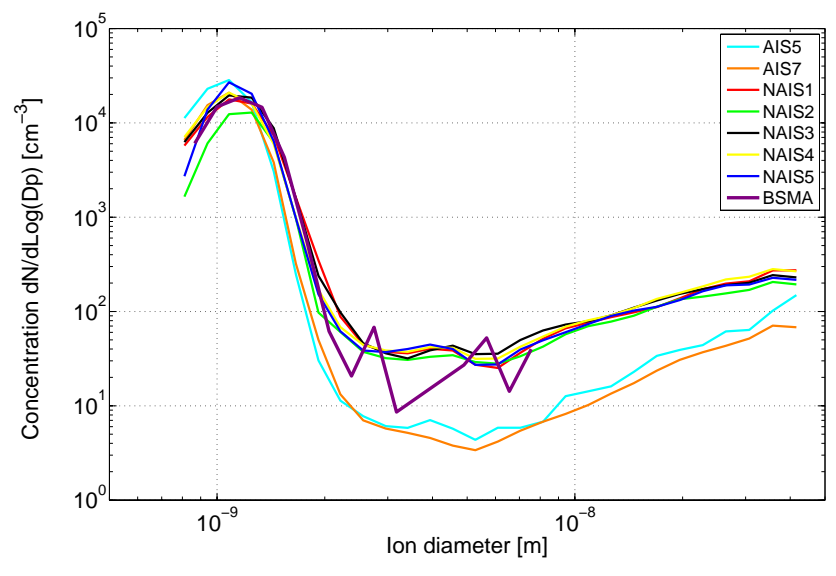

Fig. 12. Two day average negative ion number size distribution measured simultaniously with several (N)AISs.

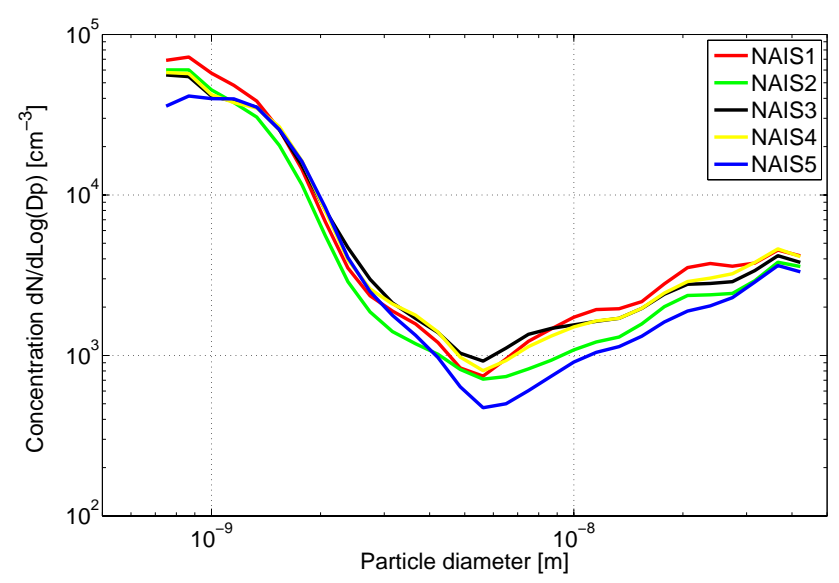

Fig. 13. One day average particle number size distribution measured simultaniously with several NAISs (negative column).

\subsection{Intercomparisons}

Ion and particle size distibutions, measured simultaneously with the different (N)AISs, showed consistant results between the AISs and the NAISs (Figs. 12 and 13). In cluster ion sizes the average AIS, NAIS and BSMA ion size distribution was similar. However, above $2 \mathrm{~nm}$, their results diverged and the NAISs detected higher numbers of negative (Fig. 12) and also positive ions (not shown here). This is partly thought to be due to the different inversion of the NAIS. The background noise level was higher in the NAISs increasing the concentration when the total concentration was low. At higher concentrations the AIS and the NAIS spectra were similar at all size fractions. That explains why the difference was not observed in calibrations where the concentrations were high. All instruments which use electrometers in detecting particles have the same problem with noise in low 


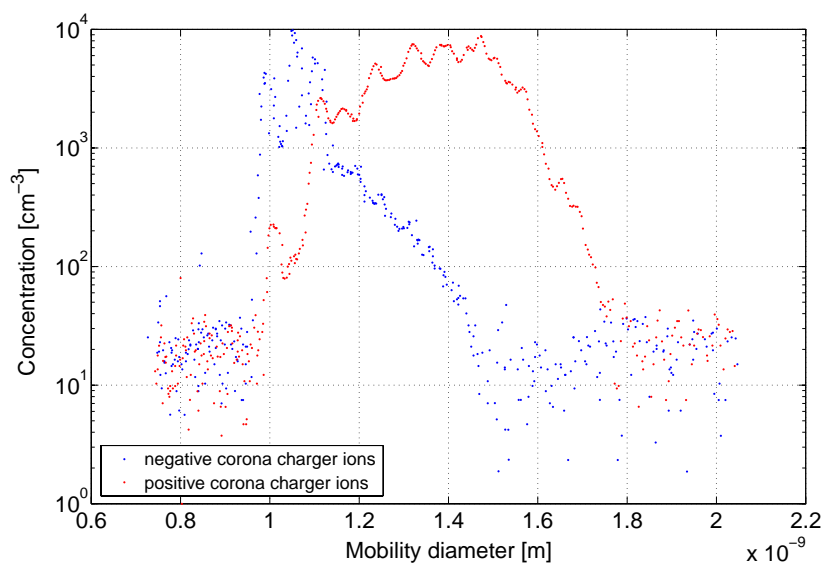

Fig. 14. Corona ions produced by the NAIS charger in room air.

concentrations and it is difficult to overcome. In atmospheric measurements, for example during nucleation events when the concentrations of intermediate and big ions are high, the different AISs and NAISs measure similar ion concentrations and the noise is negligible. In addition, the average total particle number size distributions measured with the five tested NAISs showed coinciding results, even though the post-filter adjustements were slightly drifted (Fig. 13).

\subsection{Ions produced in NAIS corona charger}

The measurement of neutral particles with the NAIS relies on the known charging probability of the particles. The corona discharging method is used for charging. In corona charging, the size and the concentration of charger ions depend on the corona voltage (e.g. Tamm et al., 1992). As the positive ions move more slowly than negative, the corona current is adjusted a few nA larger in the NAIS positive corona charger. This can also increase the size of the positive corona ions. The size of these ions determines the lowest theoretical particle detection limit of the NAIS.

The Herrmann DMA coupled with the aerosol electrometer was used to test the mobility distribution of the corona ions. In room air measurements in NTP-conditions, the NAIS positive corona ions were smaller than $1.8 \mathrm{~nm}$, whereas the negative ions were below $1.5 \mathrm{~nm}$ (Fig. 14). However, due to the transfer function broadening a part of these ions are detected at bigger sizes. Thus, the lowest detection limit can be set between 2 to $3 \mathrm{~nm}$, being smaller in negative and larger in positive polarity. The limit can be further decreased if the measured cluster concentration if high. The corona charger ion production depends also on the air particle composition and the relative humidity. Thus, the determined limit is environment dependent and should be tested in changing environmental conditions.

\section{Discussion and conclusions}

There is a great demand for sub- $3 \mathrm{~nm}$ cluster measurements (Kulmala et al., 2004b, 2007a). The (N)AIS is a recently developed instrument cabable of detecting below $3 \mathrm{~nm}$ neutral and ionic clusters. The focus of this work was to calibrate the $(\mathrm{N})$ AISs so that they could be reliably used for cluster studies. Considering the short time period from development, and the fact that the (N)AIS is used to capture nanometer-sized ions and particles, its performance was discovered good.

While proper calibration methods of smallest cluster ions have been lacking so far, the (N)AIS relies on purely theoretical measuring channel transfer functions. According to our calibrations, the theoretical trasfer functions worked well for monomobile cluster ions when using large calibration ion concentrations. Both the mobility and the concentration were measured accurately, althought the monomobile mobility peak diverged to 3 to 5 channels in the (N)AISs. This magnitude of the deviation was expected and due to diffusional losses of ions and the ratio between aerosol and sheath flow used in the (N)AIS.

The atmospheric ion distribution is, however, polydisperse. Some discrepancies were observed between theoretical and measured (N)AIS channel transfer functions when DMA selected nearly monomobile calibration ions were employed. The transfer function had a tail towards smaller mobilities, resulting in a drift of the measured ion mobility. In positive polarity, the peak of the transfer function was as well slightly shifted. The summarised result, based on different calibrations, was that $(\mathrm{N})$ AISs detected the negative ions at $36 \pm 16 \%$ larger mobilities and the positive ions at at $39 \pm 15 \%$ larger mobilities as compared to the DMA selected reference mobilities. It was assumed that the selected ion distribution remained unaltered during the $1.5 \mathrm{~s}$ residence time, which is unsure in case of the very smallest, possibly instable, ions. However, the about $40 \%$ mobility drift might also be related to some turbulence inside the instrument. As the difference was mainly congruent with size, it can be taken into account in future data inversion programs. Final goal, however, is to inspect the reasons behind the transfer function shape and to improve the design of the (N)AIS to be able to avoid the tail.

At high calibration ion and aerosol concentrations the difference between the concentrations measured by the (N)AIS and the reference instrument (CPC or aerosol electrometer) was small. When calibration aerosol concentration decreased significantly, the (N)AIS detected elevated concentrations. This was expected to be partly due to the background noise. Additionally at sizes below $1.5 \mathrm{~nm}$ (positive) and below $3 \mathrm{~nm}$ (negative) the ion spectrometers detected higher ion concentrations when compared to the aerosol electrometer, but in case of monomobile standards, the concentration difference was not as evident. However, the (N)AIS results seem to be reliable at moderate and high ion and aerosol concentrations. The results in the cluster ion (below $1.5 \mathrm{~nm}$ ) region might 
need some reconsideration and more calibrations should be performed. The neutral particle concentrations measured by NAISs were on average within $\pm 50 \%$ of the reference CPC concentrations.

There was a difference between the AIS and the NAIS in measuring atmospheric ions at small concentrations. Again, one suspected reason was the background noise, which was slightly higher in the NAIS due to different inverters. In calibrations, by contrast, no difference was detected between the AIS and the NAIS. Both the concentration and the mobility calibration results showed only small deviations between the instruments at all size ranges.

To be able to calibrate all (N)AISs within a reasonable time period, the time per one measurement was limited to about one minute. This increases the statistical error and noise, and decreases the reliability of the calibrations. A part of the problems observed when using low calibration ion concentrations might originate from the use of such a short time resolution.

In addition, a measurement of corona charger ion size distribution was performed in room air, and in NTP-conditions. The corona ions were below $1.8 \mathrm{~nm}$ (positive) and $1.5 \mathrm{~nm}$ (negative) in diameter. However, a part of the ions are detected at bigger sizes due to the transfer function broadening. Based on this, in clean condisions with low particle numbers, the lowest cut-off size in neutral particle detection with the NAIS is $2-3 \mathrm{~nm}$, being smaller in negative polarity. Below the cut-off size, the charger ions from the corona charger might increase the measurement signal and the increase is not necessarily a constant value. However, when the concentration of the measured particles below $3 \mathrm{~nm}$ is high, the cut-off size will decrease as the number of charger ions becomes insignificant compared to the number of measured particles. This is the case in atmospheric measurements for example during nucleation, when even concentrations of $1.5 \mathrm{~nm}$ particles can be measured at negative polarity.

Acknowledgements. The authors want to acknowledge the laboratory staff and people helping in calibration measurements. Toomas Bernotas and Ilmar Lipping are acknowledged for collaboration by preparation of some calibration equipment. The work was supported by EU project EUCAARI (No. 036833-2) and partly by the grant no. 6988 of the Estonian Science Foundation.

Edited by: V.-M. Kerminen

\section{References}

Andronache, C., Grönholm, T., Laakso, L., Phillips, V., and Venäläinen, A.: Scavenging of ultrafine particles by rainfall at a boreal site: observations and model estimations, Atmos. Chem. Phys., 6, 4739-4754, 2006,

http://www.atmos-chem-phys.net/6/4739/2006/.

de Juan, L. and Fernández de la Mora, J.: Size analysis af nanoparticles and ions: Running a Vienna DMA of near optimal length at Reynolds numbers up to 5000, J. Aerosol Sci., 29, 617-626, 1998.

Eichler, T.: A Differential Mobility analyzer for ions and nanoparticles: Laminar flow at high Reynolds numbers, Senior Graduation Thesis presented to Fachhochschule Offenburg, Germany, May 1997.

Fernández de la Mora, J. and Attoui, M.: A DMA covering the 1$100 \mathrm{~nm}$ particle size range with high resolution down to $1 \mathrm{~nm}$, Abstract of the EAC 2007, Saltzburg, Austria, 9-14 September, 2007.

Fernández de la Mora, J., de Juan, L., Eichler, T., and Rosell, J.: Differential mobility analysis of molecular ions and nanometer particles, Trend. Anal. Chem., 17, 328-339, 1998.

Herrmann, W., Eichler, T., Bernardo, N., and Fernández de la Mora, J.: Turbulent transition arises at Re 35000 in a short Viennatype DMA with a large laminarizing inlet, Abstract to the annual conference of the AAAR, St. Louis, MO, 6-10 October, 2000.

Hirsikko, A., Yli-Juuti, T., Nieminen, T., Vartiainen, E., Laakso, L., Hussein, T., and Kulmala, M.: Indoor and outdoor air ion and aerosol particles in the urban atmosphere of Helsinki: characteristics, sources and formation, Boreal Env. Res., 12, 295-310, 2007.

IPCC2007: Summary for Policymakers. In: Climate Change 2007: The Physical Science Basis, in: Contribution of Working Group I to the Fourth Assessment Report of the Intergovernmental Panel on Climate Change, edited by: Solomon, S., Qin, D., Manning, M., Chen, Z., Marquis, M., Averyt, K. B., Tignor, M., and Miller, H. L., Cambridge University Press, Cambridge, United Kingdom and New York, NY, USA.

Kulmala, M., Riipinen, I., Sipilä, M., Manninen, H., Petäjä, T., Junninen H., Dal Maso, M., Mordas, G., Mirme, A., Vana, M., Hirsikko, A., Laakso, L., Harrison, R. M., Hanson, I., Leung, C., Lehtinen, K. E. J., and Kerminen, V.-M.: Toward Direct Measurement of Atmospheric Nucleation, Science, 318, 89-92, doi:10.1126/science.1144124, 2007a.

Kulmala, M., Asmi, A., and Lappalainen, H.: European Integrated Project on Aerosol Cloud Climate Air Quality Interactions - EUCAARI, Abstract of the EAC 2007, Saltzburg, Austria, 9-14 September, 2007b.

Kulmala, M., Lehtinen, K. E. J., and Laaksonen, A.: Cluster activation theory as an explanation of the linear dependence between formation rate of $3 \mathrm{~nm}$ particles and sulphuric acid concentration, Atmos. Chem. Phys., 6, 787-793, 2006, http://www.atmos-chem-phys.net/6/787/2006/.

Kulmala, M., Lehtinen, K. E. J., Laakso, L., Mordas, G., and Hämeri, K.: On the existence of neutral atmospheric clusters, Boreal Env. Res., 10, 79-87, 2005.

Kulmala, M., Laakso, L., Lehtinen, K. E. J., Riipinen, I., Dal Maso, M., Anttila, T., Kerminen, V.-M., Hõrrak, U., Vana, M., and Tammet, H.: Initial steps of aerosol growth, Atmos. Chem. Phys., 4, 2553-2560, 2004a, http://www.atmos-chem-phys.net/4/2553/2004/.

Kulmala, M., Vehkamäki, H., Petäjä, T., Dal Maso, M., Lauri, A., Kerminen, V.-M., Birmili, W., and McMurry, P. H.: Formation and growth of ultrafine atmospheric particles: a review of observations, J. Aerosol Sci., 35, 143-176, 2004b.

Laakso, L., Laakso, H., Aalto, P. P., Keronen, P., Petäjä, T., Nieminen, T., Pohja, T., Siivola, E., Kulmala, M., Kgabi, N., Molefe, M., Mabaso, D., Phalatse, D., Pienaar, K., and Kerminen, V.- 
M.: Basic characteristics of atmospheric particles, trace gases and meteorology in a relatively clean Southern African Savannah environment, Atmos. Chem. Phys., 8, 4823-4839, 2008, http://www.atmos-chem-phys.net/8/4823/2008/.

Laakso, L., Grönholm, T., Kulmala, L., Haapanala, S., Hirsikko, A., Lovejoy, E. R., Kazil, J., Kurtén, T., Boy, M., Nilsson, E. D., Sogachev, A., Riipinen, I., Stratmann, F., and Kulmala, M.: Hotair balloon as a platform for boundary layer profile measurements during particle formation, Boreal Env. Res., 12, 279-294, 2007.

Laakso, L., Kulmala, M., and Lehtinen, K. E. J.: Effect of condensation rate enhancement factor on 3-nm (diameter) particle formation in binary ion-induced and homogeneous nucleation, J. Geophys. Res., 108(D18), 4574, doi:10.1029/2003JD003432, 2003.

Laakso, L., Mäkelä, J. M., Pirjola, L., and Kulmala, M.: Model studies of ion-induced nucleation in the atmosphere, J. Geophys. Res., 107(D20), 4427, doi:10.1029/2002JD002140, 2002.

Mirme, A., Tamm, E., Mordas, G., Vana, M., Uin, J., Mirme, S., Bernotas, T., Laakso, L., Hirsikko, A., and Kulmala, M.: A widerange multi-channel Air Ion Spectrometer, Boreal Env. Res., 12, 247-264, 2007.

Reischl G. P., Mäkelä, J. M., and Necid, J.: Performance of Vienna Type Differential Mobility Analyzer at 1.2-20 Nanometer, Aerosol Sci. Technol., 27, 651-672, 1997.

Rosser, S. and Fernández de la Mora, J.: DMA of high resolution and high flow rate, Aerosol Sci. and Technology, 39(12), 11911200, 2005.

Sihto, S.-L., Kulmala, M., Kerminen, V.-M., Dal Maso, M., Petäjä, T., Riipinen, I., Korhonen, H., Arnold, F., Janson, R., Boy, M., Laaksonen, A., and Lehtinen K. E. J.: Atmospheric sulphuric acid and aerosol formation: implications from atmospheric measurements for nucleation and early growth mechanisms, Atmos. Chem. Phys, 6, 4079-4091, 2006.

Suni, T., Kulmala, M., Hirsikko, A., Bergman, T., Laakso, L., Aalto, P. P., Leuning, R., Cleugh, H., Zegelin, S., Hughes, D., van Gorsel, E., Kitchen, M., Vana, M., Hõrrak, U., Mirme, S., Mirme, A., Sevanto, S., Twining, J., and Tadros, C.: Formation and characteristics of ions and charged aerosol particles in a native Australian Eucalypt forest, Atmos. Chem. Phys., 8, 129-139, 2008, http://www.atmos-chem-phys.net/8/129/2008/.

Tamm, E., Mirme, A., and Kikas, Ü.: Corona discharge as a generator of nanometer-range monodisperse aerosol, Acta Commentat. Univ. Tartu. (1954-1989), 947, 80-88, 1992.
Tammet, H.: Continuous scanning of the mobility and size distribution of charged clusters and nanometer particles in atmospheric air and the Balanced Scanning Mobility Analyzer BSMA, Atm. Res., 82, 523-535, 2006.

Ude, S. and Fernández de la Mora, J.: Molecular monodisperse mobility and mass standards from electrosprays of tetra-alkyl ammonium halides, J. Aerosol Sci., 36, 1224-1237, 2005.

Vana, M., Virkkula, A., Hirsikko, A., Aalto, P., Kulmala, M., and Hillamo, R.: Air Ion Measurements During a Cruise from Europe to Antarctica, Nucleation and Atmospheric Aerosols, 17th International Conference, Galway, Ireland, 368-372, doi:10.1007/978-1-4020-6475-3_75, 2007.

Vartiainen, E., Kulmala, M., Ehn, M., Hirsikko, A., Junninen, H., Petäjä, T., Sogacheva, L., Kuokka, S., Hillamo, R., Skorokhod, A., Belikov, I., Elansky, N., and Kerminen, V.-M.: Ion and particle number concentrations and size distributions along the TransSiberian railroad, Boreal Env. Res., 12, 375-396, 2007.

Venzac, H., Sellegri, K., and Laj, P.: Nucleation events detected at the high altitude site of the Puy de Dôme Research Station, France, Boreal Env. Res., 12, 397-408, 2007.

Virkkula, A., Hirsikko, A., Vana, M., Aalto, P. P., Hillamo, R., and Kulmala, M.: Charged particle size distributions and analysis of particle formation events at the Finnish Antarctic research station Aboa, Boreal Env. Res., 12, 397-408, 2007.

Weber, R. J., Marti, J., McMurry, P. H., Eisele, F., Tanner, D. J., and Jefferson, A.: Measured atmospheric new particle formation rates: implications for nucleation mechanisms, Chem. Engin. Comm., 151, 53-64, 1996.

Winkler, P. M., Steiner, G., Vrtala, A., Vehkamäki, H., Noppel, M., Lehtinen, K. E. J., Reischl, G. P., Wagner, P. E., and Kulmala, M.: Heterogeneous Nucleation Experiments Bridging the Scale from Molecular Ion Clusters to Nanoparticles, Science, 7, 1374-1377, doi:10.1126/science.1149034, 2008.

Winklmayr, W., Reischl, G. P., Lindner, A. O., and Berner, A.: A New Electromobility Spectrometer for the Measurement of Aerosol Size Distributions in the Size Range From 1 to $1000 \mathrm{~nm}$, J. Aerosol Sci. 22, 289-296, 1991.

Yu, F. and Turco R. P.: Ultrafine aerosol formation via ion-mediated nucleation, Geophys. Res. Lett., 27, 883-886, 2000. 